\title{
In-silico molecular docking analysis of some plant derived molecules for anti-inflammatory inhibitory activity
}

\author{
L. Thamaraiselvi', T. Selvankumar', E. G. Wesely" ${ }^{1 *}$ N. Vinod Kumar ${ }^{3}$ * \\ 'Department of Botany, A.A. Government Arts College, Namakkal 637 002, Tamil Nadu, India, ${ }^{2}$ Department of \\ Biotechnology, Mahendra Arts and Science College, Kalippatti 637507 , Tamilnadu, India, ${ }^{3}$ School of Chemical and \\ Biotechnology, SASTRA Deemed to be University, Thanjavur 613 401, Tamil Nadu, India
}

Received: November 12, 2020 Revised: January 28, 2021 Accepted: February 12, 2021 Published: March 17, 2021

*Corresponding Author: N.Vinod Kumar

E-mail: nvkibt@gmail.com

\begin{abstract}
Herbs are essential resources for drug discovery. However, numerous challenges stand in front of the scientific community to discover novel drugs from herbs. To explore the validation behind the precious knowledge of traditional medicine, we focused on achieving virtual screening to detect the potential medicines from the herbs. Five bioactive compounds from known anti-inflammatory medicinal plants were examined through molecular docking against cyclooxygenase-2 (COX-2) and inducible Nitric Oxide Synthase (iNOS), using AutoDock 4.2. The docking of selected ligands with COX-2 showed the binding energy varying from $-6.15 \mathrm{Kcal} / \mathrm{mol}$ to $11.24 \mathrm{Kcal} / \mathrm{mol}$. The docking energies of identified ligands with iNOS were generated ranging from $-3.85 \mathrm{kcal} / \mathrm{mol}$ to $-6.99 \mathrm{kcal} / \mathrm{mol}$. Among the tested ligands, it was noted that $6 \mathrm{urs}-12$-en-24-oic acid showed the best binding energy than other compounds with the lowest binding energy and highest binding affinity with both anti-inflammatory target proteins COX-2 and iNOS. The in silico study validates the potential phytochemical compound of the medicinal herb that contributes to anti-inflammatory activity with low toxicity and minimal side effects.
\end{abstract}

KEYWORDS: Autodock, CADD, COX-2, Drug Discovery, iNOS

\section{INTRODUCTION}

A significant challenge of contemporary medicine is to make substances that regulate certain enzymes while leaving related isozymes unaffected. The two essential proteins, namely Cyclooxygenase-2 (COX-2) and inducible Nitric Oxide Synthase (iNOS) are essential mediators of an inflammatory process. Nonsteroidal Anti-inflammatory Drugs (NSAIDs) like Indomethacin act via inhibition of COX enzyme, COX catalyzes the first step of the biosynthesis of prostaglandins (Dannhardt and Kiefer, 2001). Prostaglandins (PGs), found in most of the tissues and organs, are the arachidonic acid metabolites of the Cyclooxygenase (COX) pathway and are significant mediators in the regulation of the inflammation and immune function (Smith et al., 2000). It has been shown that COX enzyme exists in two isoforms COX-1 and COX-2 (Marnett et al., 1999). In regards to amino acid composition, these enzymes are about 60\% identical, and their catalytic areas are commonly conserved (Picot et al., 1994). The COX-l enzyme is responsible for maintaining gastric and renal integrity, and COX-2 is an inducible enzyme responsible for the production of proinflammatory PGs, causing inflammation and pain (Seibert et al., 1994). The COX-2 inhibitors are useful for the relief of chronic pain in elderly patients with osteoarthritis and rheumatoid arthritis (Savage, 2005).

Inducible Nitric Oxide Synthase (iNOS), is another inducible enzyme, that plays a significant role in the overproduction of nitric oxide (NO) and has been implicated in several pathophysiological states, for example; various inflammation, septic shock, vascular dysfunction in diabetes and cancer patients (Halliwell, 1994). Three homologous NOS isozymes [inducible NOS (iNOS), endothelial NOS (eNOS), and neuronal NOS (nNOS)] catalyze the five-electron, two-step oxidation of L-arginine (L-Arg) to form a nitric oxide which is an important biological signalling molecule and cellular cytotoxic (Griffith and Stuehr, 1995). The constitutive isozymes, eNOS and nNOS, function to produce low levels of $\mathrm{NO}$ predominantly for blood pressure regulation and nerve function, respectively. In contrast, iNOS is induced by microbial products, such as lipopolysaccharide (LPS) and inflammatory cytokines such as interleukin-l (IL-1), tumour necrosis factor- $\alpha(\mathrm{TNF}-\alpha)$ and interferon- $\gamma(\mathrm{INF}-\gamma)$ in macrophages and some other cells (Hämäläinen et al., 2007). COX-2 and iNOS overexpression have been observed in many human invasive malignant tumours, e.g. breast, lung, prostate, bladder, colorectal cancer and malignant melanoma (Ermert

Copyright: $\odot$ The authors. This article is open access and licensed under the terms of the Creative Commons Attribution License (http:// creativecommons.org/licenses/by/4.0/) which permits unrestricted, use, distribution and reproduction in any medium, or format for any purpose, even commercially provided the work is properly cited. Attribution - You must give appropriate credit, provide a link to the license, and indicate if changes were made. 
et al., 2003). Therefore, the modulation of iNOS and COX-2 can be an excellent approach for the administration of illness going along with the overflow of NO and PGs.

The molecular modelling with docking simulation strategy is an approach to check out the communication between the ligand and macromolecular targets. Understanding of the favoured alignment subsequently may be used to anticipate the strength of association or binding affinity in between two molecules utilizing for scoring functions (Musfiroh et al., 2013).

The docking principle is done by positioning the ligand right into the binding receptor pockets; further, the molecules based on its form-similarity, and also on its attributes like its electrostatic nature (Kroemer, 2003). Usually, the binding in between drugs and even receptors is categorized as weak as well as non-covalent interaction to ensure that the generated effect is reversible. This inhibition can occur if the active compound functions connect with the target-binding pockets in numerous ways. These are Van der Waals communication, hydrophobic communication, and also hydrogen bond formation in which the last one has the best affinity with distance in between 2.5-3.2 $\AA$ (Schaeffer, 2008).

In this paper, the potential inetarctions of selected phytochemicals with proteins like iNOS and COX-2 is studied using molcelar docking approach. Though many antiinflammatory phytochemicals have been studied previously, more selective and specific phytochemicals were screened in this study.

\section{MATERIALS AND METHODS}

\section{Preparation of Protein Structures}

The experimental coordinates of COX-2 (PDB ID:6Y3C) and iNOS (PDB ID: 3HR4) arrangements were taken from PDB (rcsb.org/pdb/). Ligands were eliminated from the binding sites of both COX-2 and iNOS for docking research studies (Figure 1). Heteroatoms were removed and also polar hydrogen atoms were added to protein structures, and also partial atomic charges were assigned. The proteins were saved in PDB format; atomic

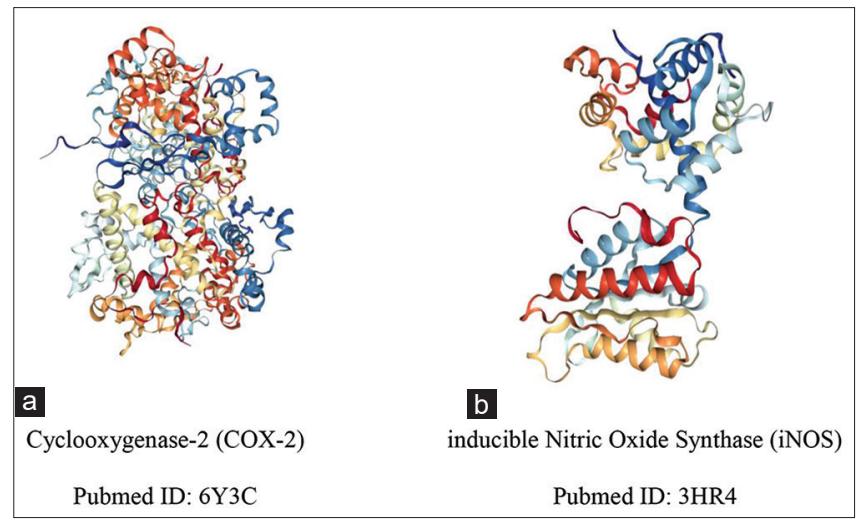

Figure 1: 3D Structure of target proteins without ligands (a) COX-2 (6Y3C) and (b) iNOS (3HR4) solvation parameters were assigned and converted finally into PDBQ format. The Molecular displays were created by RasMol (openrasmol.org/).

\section{Preparation of Ligands}

Medicinal plants with anti-inflammatory properties were selected from the previous literatures (Aleem et al., 2020; Jeewanthi et al., 2020; Jamshed et al., 2019) and potential compounds identified from the selected plants were used as ligands in this study. The 3D structures of the selected ligands namely 6 urs-12-en-24-oic acid (Figure 2a) and $\beta$-Amyrin (Figure 2b) from Plumbago zeylanica, 10,12-Docasadiyndioic Acid (Figure 2c) and l(Ethynyltrimethylsilyl-2)-1-Chloro2-Ethyl-2-methyl cyclopropane (Figure 2d) from Neolitsea cassia, and Androstane (Figure 2e) from Wrightia tinctoria was collected from Pubchem (http://pubchem.ncbi.nlm.nih. gov), a compound database. The collected Structure Data File (SDF) files of identified ligands from the PubChem database were converted into Protein Data Bank (PDB) format using the EduPymol version 1.7.4.4.

\section{Protein-Ligand Docking}

Docking of ligands was carried out against COX-2 and iNOS using AutoDock 4.2. AutoDock is a widely distributed public domain molecular docking software (Thomas et al., 2008).

It includes elements like AutoGrid and also AutoTors as well as uses the Lamarckian genetic algorithm to produce a collection of possible conformations. This program addresses the versatile docking of the ligands instantly right into a recognized protein structure. The proteins for each docking were kept rigid and torsional flexibility was permitted to the ligands. The rotatable bonds in the ligands were defined using AutoTors, and also grid maps were computed using AutoGrid. The search was conducted in grid points of $80 \times 80 \times 80$ with $0.675 \mathrm{~A}^{\circ}$ spacing for COX-2 (Honmore et al., 2016; Zhang et al., 2019) and 60x60x60 with $0.503 \mathrm{~A}^{\circ}$ spacing for iNOS in three dimensions built in $\mathrm{x}, \mathrm{y}$, and $\mathrm{z}$ directions on the binding site of macromolecules (Zhang et al., 2019). Each docking experiment consists of 50 docking runs with 150 individuals. The default settings were used for all other parameters. The AutoDock results give the binding energy and bound conformations of docked structures. Subsequently, the result of the docking procedure was examined utilizing EduPymol variation 1.7.4.4.

\section{RESULTS AND DISCUSSION}

In the present investigation, anti-inflammatory properties of the selected compounds namely 6 urs-12-en-24-oic acid, $\beta$-Amyrin, 10,12-Docasadiyndioic Acid, 1(Ethynyltrimethylsilyl-2)-1Chloro-2-Ethyl-2-methyl cyclopropane and Androstane were evaluated using Autodock 4.2 molecular docking studies.

The identified phytocompounds 6 urs-12-en-24-oic acid, $\beta$-Amyrin, 10,12-Docasadiyndioic Acid, 1(Ethynyltrimethylsilyl2)-1-Chloro-2-Ethyl-2-methyl cyclopropane, and Androstane 
individual docking studies were performed using AutoDock 4.2 against COX-2 (Table 1 and Figure 3) and iNOS (Table 2 and Figure 4) enzymes. The selected ligand structures were downloaded from the Pubchem database. Amongst the different binding poses in the active site, the very best posture for both the ligands and also a lot of regular conformation was chosen based on docking energy. The 6 urs-12-en-24-oic acid, $\beta$-Amyrin, 10,12-Docasadiyndioic Acid, 1 (Ethynyltrimethylsilyl-

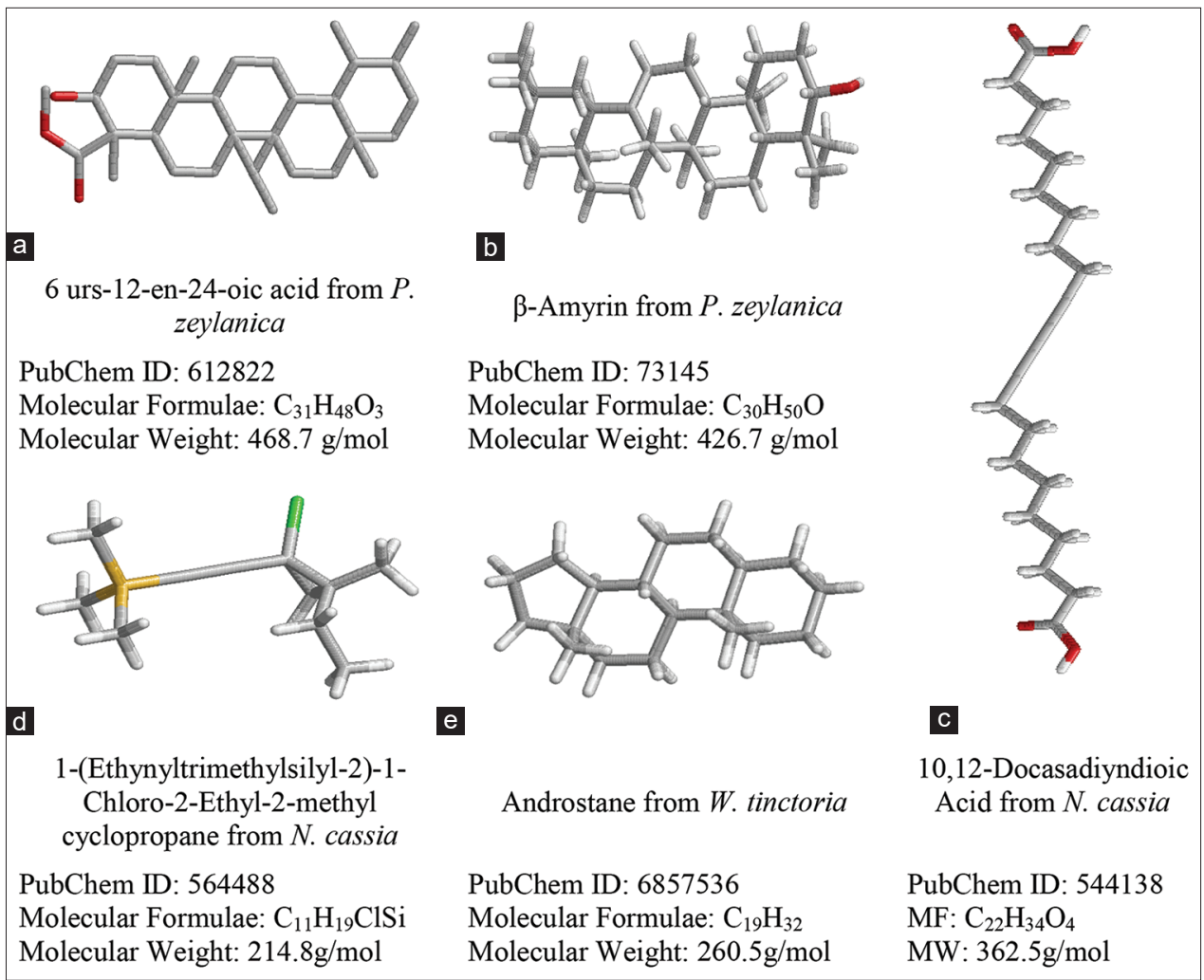

Figure 2: Chemical Structure of Identified Phytocompounds investigated

Table 1: Molecular Docking statistics of the Human Cyclooxygenase-2 and Identified Ligands Complex

\begin{tabular}{|c|c|c|c|c|c|}
\hline & $\begin{array}{l}6 \text { urs-12-en-24-oic acid } \\
\text { from } P \text {. zeylanica }\end{array}$ & $\begin{array}{l}\beta \text {-Amyrin from } \\
\text { P. zeylanica }\end{array}$ & $\begin{array}{l}\text { 10,12-Docasadiyndioic } \\
\text { Acid from } N \text {. cassia }\end{array}$ & $\begin{array}{l}\text { 1(Ethynyltrimethylsilyl- } \\
\text { 2)-1-Chloro-2-Ethyl- } \\
\text { 2-methyl cyclopropane } \\
\text { from } N \text {. cassia }\end{array}$ & $\begin{array}{l}\text { Androstane } \\
\text { from } \\
\text { W. tinctoria }\end{array}$ \\
\hline Binding energy $(\mathrm{Kcal} / \mathrm{mol})$ & -11.24 & -7.8 & -6.31 & -6.15 & -9.67 \\
\hline Ligand Efficiency & -0.33 & 0.25 & 0.24 & -0.47 & -0.51 \\
\hline Inhibition Constant & $5.79 \mathrm{nM}$ & $1.91 \mu \mathrm{M}$ & $23.55 \mu \mathrm{M}$ & $31.25 \mu \mathrm{M}$ & $82.09 \mathrm{nM}$ \\
\hline $\begin{array}{l}\text { Intermolecular Energy } \\
\text { (Kcal/mol) }\end{array}$ & -12.13 & -8.1 & -12.58 & -7.04 & -9.67 \\
\hline $\begin{array}{l}\mathrm{vdW}+\mathrm{Hbond}+\text { desolv } \\
\text { Energy }(\mathrm{Kcal} / \mathrm{mol})\end{array}$ & -12.15 & -8.02 & -10.34 & -7.03 & -9.67 \\
\hline Electrostatic Energy & 0.02 & -0.08 & -2.24 & -0.01 & 0.0 \\
\hline Total Internal Energy & 0.22 & 0.04 & -0.74 & -0.32 & 0.0 \\
\hline Torsional Free Energy & 0.89 & 0.3 & 6.26 & 0.89 & 00 \\
\hline RMSD & 67.9 & 71.91 & 55.36 & 68.28 & 56.27 \\
\hline $\begin{array}{l}\text { Number of Hydrogen } \\
\text { bonds }\end{array}$ & 3 & 3 & 5 & 0 & 0 \\
\hline $\begin{array}{l}\text { Hydrogen bond } \\
\text { Interaction }\end{array}$ & $\begin{array}{l}\text { Thr212-N: 033-Ligand } \\
\text { Thr212-0G1:031-Ligand } \\
\text { Asn382-ND2:031-Ligand }\end{array}$ & $\begin{array}{c}\text { Asn382-N: 033-Ligand } \\
\text { Thr212-0G1:031-Ligand } \\
\text { Asn382-ND2:031- } \\
\text { Ligand }\end{array}$ & $\begin{array}{l}\text { Gln372-N: 015-Ligand } \\
\text { Lys532-NZ: 013-Ligand } \\
\text { His43-N: 025-Ligand } \\
\text { GIn44-N: 027-Ligand } \\
\text { Lys468-0-H28-Ligand }\end{array}$ & NA & NA \\
\hline Hydrogen Bond Length & $\begin{array}{l}3.2 \\
2.5 \\
2.9\end{array}$ & $\begin{array}{l}3.2 \\
2.9 \\
3.3\end{array}$ & $\begin{array}{l}3.5 \\
2.7 \\
3.2 \\
2.9 \\
2.1\end{array}$ & NA & NA \\
\hline
\end{tabular}




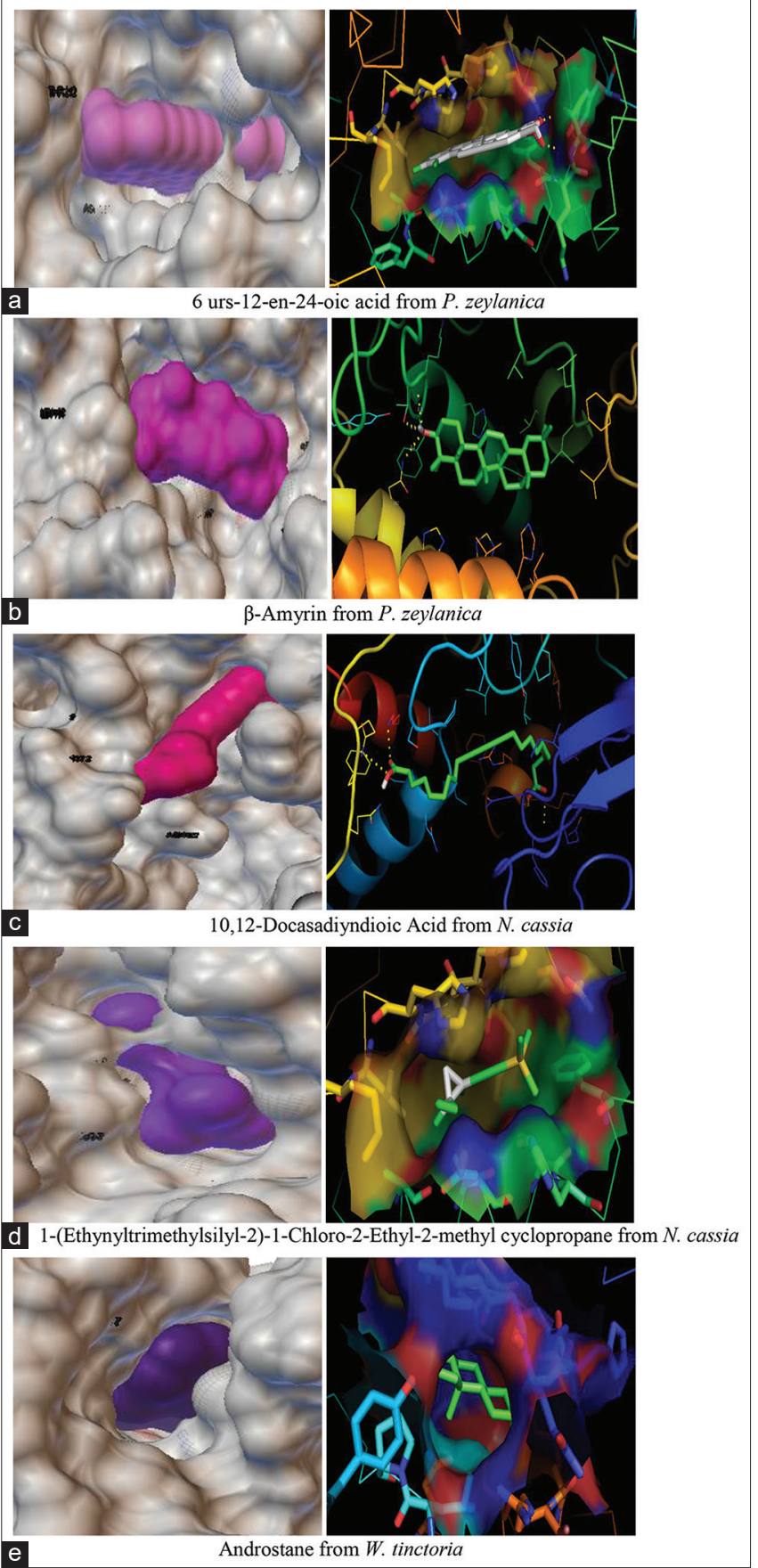

Figure 3: 3D Structure of Human Cyclooxygenase-2 and Ligands Complex

2)-1-Chloro-2-Ethyl-2-methyl cyclopropane and Androstane with COX-2 (Table 1 and Figure 3) showed docking energy of $-11.24 \mathrm{kcal} / \mathrm{mol},-7.8 \mathrm{kcal} / \mathrm{mol},-6.31 \mathrm{kcal} / \mathrm{mol},-6.15 \mathrm{kcal} / \mathrm{mol}$ and $9.67 \mathrm{kcal} / \mathrm{mol}$ respectively (Table 1 ). The docking of 6 urs-12en-24-oic acid with COX-2 (Figure 3a) demonstrates that the best inhibitor makes three hydrogen bonds with two residues Thr212-N, Thr212-OGl and Asn382ND2 with 3.2A $2.5 \mathrm{~A}^{\circ}$ and $2.9 \mathrm{~A}^{\circ}$, respectively. Then, the complex of $\beta$-Amyrin with COX-2 also showed three hydrogen bonds with Asn382-N, Thr212-OGl and Asn382-ND2 (Figure 3b) with a bond length of $3.2 \mathrm{~A}^{\circ}, 2.9 \mathrm{~A}^{\circ}$ and $3.3 \mathrm{~A}^{\circ}$ respectively. 10,12-Docasadiyndioic

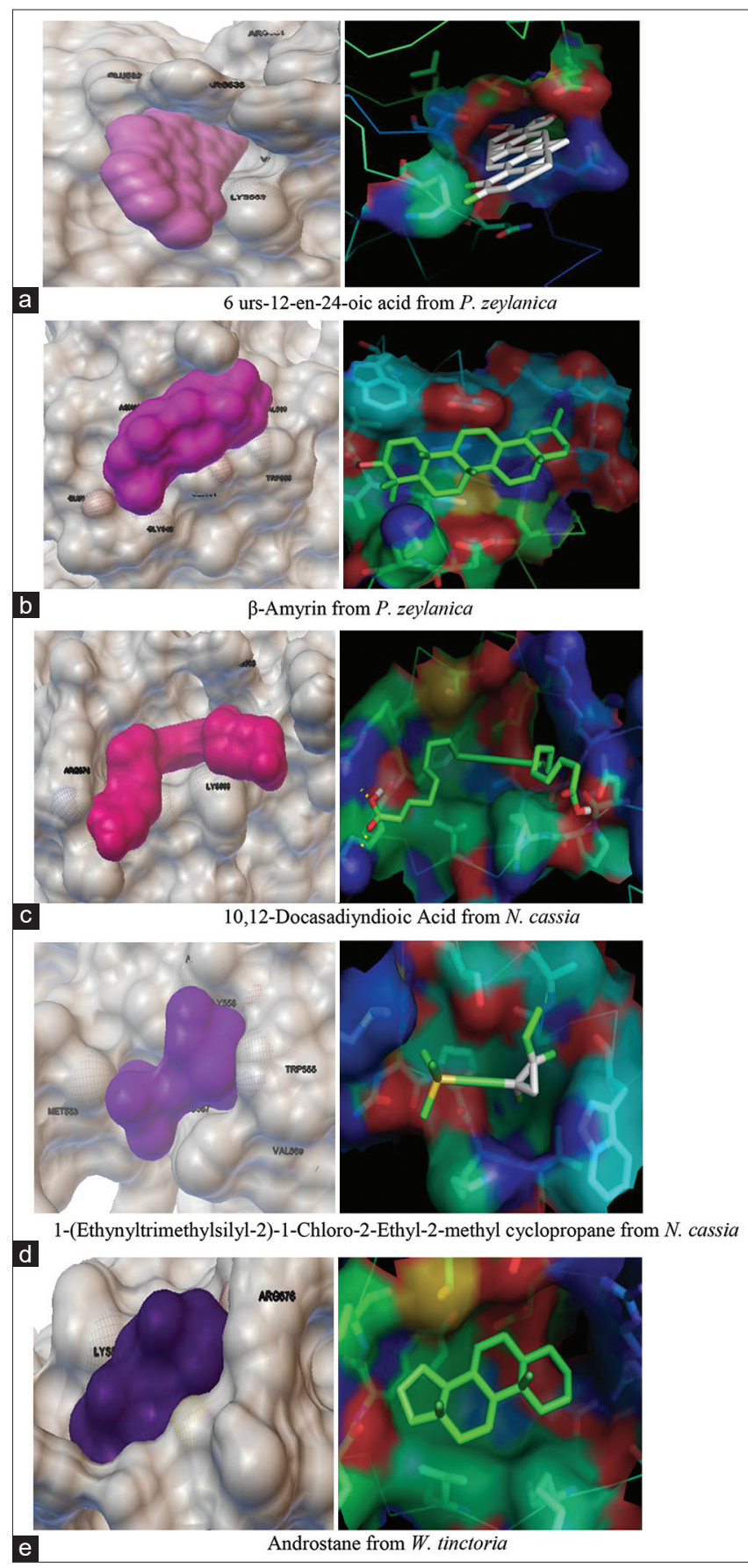

Figure 4: 3D Structure of Human inducible Nitric Oxide Synthase and Identified Ligands Complex

Acid - COX-2 interacted through 5 hydrogen bonds with residues of Gln372-N, Lys532-NZ, His43-N, Gln44-N and Lys 468-O with a bond length of $3.5 \mathrm{~A}^{\circ}, 2.7 \mathrm{~A}^{\circ}, 3.2 \mathrm{~A}^{\circ}, 2.9 \mathrm{~A}^{\circ}$ and $2.1 \mathrm{~A}^{\circ}$ respectively (Figure $3 \mathrm{c}$ ). No hydrogen bonds formed with COX-2 by rest of the two compounds 1(Ethynyltrimethylsilyl2)-1-Chloro-2-Ethyl-2-methyl cyclopropane and Androstane but interacted through other forces such as hydrophobic, Van der Waals and electrostatic forces (Figure 4d and 4e). This data is contradictory with literature reports where docking of the synthetic compounds depicted three different types of binding patterns in general. The results obtained in the present study 
Table 2: Molecular Docking statistics of the Human inducible Nitric 0xide Synthase and Identified Ligands Complex

\begin{tabular}{|c|c|c|c|c|c|}
\hline & $\begin{array}{c}6 \text { urs-12-en-24-oic acid from } \\
\text { P. zeylanica }\end{array}$ & $\begin{array}{l}\beta \text {-Amyrin from } \\
\text { P. zeylanica }\end{array}$ & $\begin{array}{l}\text { 10,12-Docasadiyndioic } \\
\text { Acid from } N \text {. cassia }\end{array}$ & $\begin{array}{l}\text { 1(Ethynyltrimethylsilyl- } \\
\text { 2)-1-Chloro-2-Ethyl- } \\
\text { 2-methyl cyclopropane } \\
\text { from } N \text {. cassia }\end{array}$ & $\begin{array}{l}\text { Androstane from } \\
\text { W. tinctoria }\end{array}$ \\
\hline $\begin{array}{l}\text { Binding energy } \\
(\mathrm{Kcal} / \mathrm{mol})\end{array}$ & -6.99 & -6.79 & -3.85 & -3.92 & -6.17 \\
\hline Ligand Efficiency & -0.21 & -0.22 & -0.15 & -0.3 & -0.32 \\
\hline Inhibition Constant & $7.54 \mu \mathrm{m}$ & $10.59 \mu \mathrm{m}$ & $1.5 \mathrm{mM}$ & $1.34 \mathrm{mM}$ & $30.27 \mu \mathrm{m}$ \\
\hline $\begin{array}{l}\text { Intermolecular Energy } \\
(\text { Kcal/mol) }\end{array}$ & -7.88 & -7.09 & -10.12 & -4.81 & -6.17 \\
\hline $\begin{array}{l}\text { vdW }+ \text { Hbond + desolv } \\
\text { Energy }(\text { Kcal/mol) }\end{array}$ & -7.93 & -7.05 & -8.04 & -4.8 & -6.16 \\
\hline Electrostatic Energy & 0.05 & -0.04 & -2.08 & -0.01 & 0.0 \\
\hline Total Internal Energy & 0.01 & 0.04 & -0.83 & -0.32 & 0.0 \\
\hline Torsional Free Energy & 0.89 & 0.3 & 6.26 & 0.89 & 0.0 \\
\hline RMSD & 40.02 & 51.49 & 48.09 & 38.56 & 41.97 \\
\hline $\begin{array}{l}\text { Number of Hydrogen } \\
\text { bonds }\end{array}$ & 2 & 1 & 4 & 0 & 0 \\
\hline $\begin{array}{l}\text { Hydrogen bond } \\
\text { Interaction }\end{array}$ & $\begin{array}{l}\text { THR540-0G1: 033-Ligand } \\
\text { THR540N: } 033 \text { Ligand }\end{array}$ & VAL596-0: H32Ligand & $\begin{array}{l}\text { Asn566-0D1: H28-Ligand } \\
\text { Lys574-0: H16-Ligand } \\
\text { Arg576-0: 015-Ligand } \\
\text { Lys574-NZ: 014-Ligand }\end{array}$ & NA & NA \\
\hline Hydrogen Bond Length & $\begin{array}{l}3.1 \\
3.0\end{array}$ & 2.1 & $\begin{array}{l}2.1 \\
2.2 \\
2.9 \\
3.0\end{array}$ & NA & NA \\
\hline
\end{tabular}

were better than the previous reports (Zhang et al., 2019; Utami et al., 2020). Use careful COX-2 inhibitors such as SC-558; the bonding was in the close vicinity of the hydrophobic pocket. The phenylsulphonamide team occupied the side pocket as well as showed binding with His 90 as well as an interaction with $\operatorname{Arg} 513$ which has also been identified as an essential residue in the binding of careful COX-2 preventions according to the site- guided mutagenesis data (Kurumbail et al., 1996).

However, in another study, docking of Diclofenac revealed that its orientation makes the residues of side pocket thereby the hydrophilic pocket of COX-2 protein is inaccessible and the phenylacetic acid moiety is orientated towards Tyr 385 and Ser530 and hence possess H-bonding interaction (Dilber et al., 2008). Ibuprofen as well as Naproxen when docked right into the active site of the COX-2 enzyme, the engaging deposits 120 were observed to be $\operatorname{Arg} 120$ and also Tyr355 (Llorens et al., 2002). This comparative analysis of literary works information and existing examination additionally suggested that the prodigiosin and also cycloprodigiosin influence the active site conformation of COX-2 protein by connecting at various area besides existing active sites and also induces the anti-inflammatory function.

Similarly, the docking energies of 6 urs-12-en-24-oic acid, $\beta$-Amyrin, 10,12-Docasadiyndioic Acid, 1 (Ethynyltrimethylsilyl2)-1-Chloro-2-Ethyl-2-methyl cyclopropane, and Androstane with iNOS was found to be $-6.99 \mathrm{kcal} / \mathrm{mol},-6.79 \mathrm{kcal} / \mathrm{mol}$, $-3.85 \mathrm{kcal} / \mathrm{mol},-3.92 \mathrm{kcal} / \mathrm{mol}$ and $-6.17 \mathrm{kcal} / \mathrm{mol}$ respectively (Table 2). Based on the in silico analysis, 6 urs-12-en-24-oic acid (Figure 4a) has the lowest value in binding free energy. At the same time, $\beta$-Amyrin (Figure $4 \mathrm{~b}$ ) and Androstane (Figure 4e) were in the second and third position with iNOS (Table 2). Though, 1(Ethynyltrimethylsilyl-2)-1-Chloro-2-Ethyl-2methyl cyclopropane (Figure 4d) has a good binding score but is not interacted by hydrogen bonds with iNOS (Table 2). It communicated through hydrophobic, electrostatic and Van der Waals interactions with iNOS. Likewise, Androstane (Figure 4e) is also not associated through hydrogen bond and electrostatic force, it is related to hydrophobic and Van der Waals interactions (Table 2). Based on the docking energies results, we deduce that 6 urs-12-en-24-oic acid has potential anti-inflammatory activity compared to the other four phytocompounds. Following the previous reports, our data also demonstrated that quercetin effectively protected iNOS-mediated nitric oxide production and neuroinflammation (Bahar et al., 2017). In iNOS, the arginine urea group forms bidentate interaction with Glu377 adjacent to the active site. It is a site of more significant competitive inhibitors that may inhibit iNOS (Fischmann et al., 1999). Catechin retained all the primary interactions shown by co-crystallized iNOS inhibitors. Catechin kept critical communication with the porphyrin ring; this porphyrin ring plays a vital role in catalytic enzyme mechanisms. In the present study, in silico docking studies revealed inhibition of iNOS by catechin.

\section{CONCLUSIONS}

In the present study, five selected phytochemicals were screened for its antinflammatory properties. Based on the molecular docking results, 6 urs-12-en-24-oic acid was found to be a better anti-inflammatory agent compared to other phytocompounds tested in this study. Though these herbal medicines are 
well known to treat the inflammation, the phytochemical contributing to the antinflammatory effect was elucidated through this study.

\section{REFERENCES}

Aleem, M. (2020). Anti-Inflammatory and Anti-Microbial Potential of Plumbago zeylanica L.: A Review. Journal of Drug Delivery and Therapeutics, 10(5-s), 229-235. https://doi.org/10.22270/jddt. v10i5-s. 4445

Bahar, E., Kim, J. Y., \& Yoon, H. (2017). Quercetin Attenuates ManganeseInduced Neuroinflammation by Alleviating Oxidative Stress through Regulation of Apoptosis, iNOS/NF-KB and HO-1/Nrf2 Pathways. International Journal of Molecular Sciences, 18(9), 1989. https://doi.org/10.3390/ijms18091989

Dannhardt, G., \& Kiefer, W. (2001). Cyclooxygenase inhibitors-current status and future prospects. European Journal of Medicinal Chemistry, 36(2), 109-126. https://doi.org/10.1016/s0223-5234(01)01197-7

Dilber, S. P., Dobric, S., Juranic, Z. D., Markovic, B. D., Vladimirov, S. M., \& Juranic, I. O. (2008). Docking studies and anti-inflammatory activity of beta-hydroxy-beta-arylpropanoic acids. Molecules (Basel, Switzerland), 13(3), 603-615. https://doi.org/10.3390/ molecules13030603

Ermert, L., Dierkes, C., \& Ermert, M. (2003). Immunohistochemical expression of cyclooxygenase isoenzymes and downstream enzymes in human lung tumors. Clinical cancer research : an official journal of the American Association for Cancer Research. 9(5), 1604-1610.

Fischmann, T. O., Hruza, A., Niu, X. D., Fossetta, J. D., Lunn, C. A., Dolphin, E., Prongay, A. J., Reichert, P., Lundell, D. J., Narula, S. K., \& Weber, P. C. (1999). Structural characterization of nitric oxide synthase isoforms reveals striking active-site conservation. Nature Structural Biology, 6(3), 233-242. https://doi.org/10.1038/6675

Griffith, O. W., \& Stuehr, D. J. (1995). Nitric oxide synthases: properties and catalytic mechanism. Annual Review of Physiology, 57, 707-736. https://doi.org/10.1146/annurev.ph.57.030195.003423

Halliwell B. (1994). Free radicals, antioxidants, and human disease: curiosity, cause, or consequence?. The Lancet, 344(8924), 721-724. https://doi.org/10.1016/s0140-6736(94)92211-x

Hämäläinen, M., Nieminen, R., Vuorela, P., Heinonen, M., \& Moilanen, E. (2007). Anti-inflammatory effects of flavonoids: genistein, kaempferol, quercetin, and daidzein inhibit STAT-1 and NF-kappaB activations, whereas flavone, isorhamnetin, naringenin, and pelargonidin inhibit only NF-kappaB activation along with their inhibitory effect on iNOS expression and NO production in activated macrophages. Mediators of Inflammation, 2007, 45673. https://doi.org/10.1155/2007/45673

Honmore, V. S., Kandhare, A. D., Kadam, P. P., Khedkar, V. M., Sarkar, D., Bodhankar, S. L., Zanwar, A. A., Rojatkar, S. R., \& Natu, A. D. (2016). Isolates of Alpinia officinarum Hance as COX-2 inhibitors: Evidence from anti-inflammatory, antioxidant and molecular docking studies. International Immunopharmacology, 33, 8-17. https://doi. org/10.1016/j.intimp.2016.01.024

Jamshed, H., Siddiqi, H. S., Gilani, A. U., Arslan, J., Qasim, M., \& Gul, B. (2019). Studies on antioxidant, hepatoprotective, and vasculoprotective potential of Viola odorata and Wrightia tinctoria. Phytotherapy Research, 33(9), 2310-2318. https://doi. org/10.1002/ptr.6411

Jeewanthi, W. S., \& Gunathilake, K. D. P. P. (2020). Isolation and
Characterization of Arabinoxylan from Leaves of Neolitsea cassia (L.) Kosterm and evaluation of Its Physicochemical and Functional Properties. South Asian Research Journal of Natural Products, 16-26. https://doi.org/10.3390/ijms12010570

Kroemer R. T. (2003). Molecular modelling probes: docking and scoring. Biochemical Society Transactions, 31(Pt 5), 980-984. https:// doi.org/10.1042/bst0310980

Kurumbail, R. G., Stevens, A. M., Gierse, J. K., McDonald, J. J., Stegeman, R. A., Pak, J. Y., Gildehaus, D., Miyashiro, J. M., Penning, T. D., Seibert, K., Isakson, P. C., \& Stallings, W. C. (1996) Structural basis for selective inhibition of cyclooxygenase-2 by anti-inflammatory agents. Nature, 384(6610), 644-648. https://doi. org/10.1038/384644a0

Llorens, O., Perez, J. J., Palomer, A., \& Mauleon, D. (2002). Differential binding mode of diverse cyclooxygenase inhibitors. Journal of Molecular Graphics and Modelling, 20(5), 359-371. https://doi. org/10.1016/S1093-3263(01)00135-8

Marnett, L. J., Rowlinson, S. W., Goodwin, D. C., Kalgutkar, A. S., \& Lanzo, C. A. (1999). Arachidonic acid oxygenation by COX-1 and COX-2. Mechanisms of catalysis and inhibition. The Journal of Biological Chemistry, 274(33), 22903-22906. https://doi.org/10.1074/ jbc. 274.33 .22903

Musfiroh, I. D. A., Muhtadi, A., Kartasasmita, R. E., \& Tjahjono, D. H. (2013). In silico study of asiatic acid interaction with inducible nitric oxide synthase (INOS) and cyclooxygenase-2 (COX-2). International Journal of Pharmacy and Pharmaceutical Sciences, 5(1), 204-207.

Picot, D., Loll, P. J., \& Garavito, R. M. (1994). The X-ray crystal structure of the membrane protein prostaglandin $\mathrm{H} 2$ synthase-1. Nature, 367(6460), 243-249. https://doi.org/10.1038/367243a0

Savage R. (2005). Cyclo-oxygenase-2 inhibitors: when should they be used in the elderly?. Drugs \& Aging, 22(3), 185-200. https://doi. org/10.2165/00002512-200522030-00001

Schaeffer, L. (2008). The role of functional groups in drug-receptor interactions. In The Practice of Medicinal Chemistry (pp. 464-480). Academic Press.

Seibert, K., Zhang, Y., Leahy, K., Hauser, S., Masferrer, J., Perkins, W., Lee, L., \& Isakson, P. (1994). Pharmacological and biochemical demonstration of the role of cyclooxygenase 2 in inflammation and pain. Proceedings of the National Academy of Sciences of the United States of America, 91(25), 12013-12017. https://doi.org/10.1073/ pnas.91.25.12013

Smith, W. L., DeWitt, D. L., \& Garavito, R. M. (2000). Cyclooxygenases: structural, cellular, and molecular biology. Annual review of biochemistry, 69, 145-182. https://doi.org/10.1146/annurev. biochem.69.1.145

Thomas, J. L., Mack, V. L., Glow, J. A., Moshkelani, D., Terrell, J. R., \& Bucholtz, K. M. (2008). Structure/function of the inhibition of human 3beta-hydroxysteroid dehydrogenase type 1 and type 2 by trilostane. The Journal of Steroid Biochemistry and Molecular Biology, 111(1-2), 66-73. https://doi.org/10.1016/j.jsbmb.2008.04.007

Utami, W., Aziz, H. A., Fitriani, I. N., Zikri, A. T., Mayasri, A., \& Nasrudin, D. (2020, June). In silico anti-inflammatory activity evaluation of some bioactive compound from ficus religiosa through molecular docking approach. In Journal of Physics: Conference Series (Vol. 1563, No. 1 , p. 012024). IOP Publishing.

Zhang, Q. L., Zhang, J., Xia, P. F., Peng, X. J., Li, H. L., Jin, H., Li, Y., Yang, J. \& Zhao, L. (2019). Anti-inflammatory activities of gentiopicroside against iNOS and COX-2 targets. Chinese Herbal Medicines, 11(1), 108-112. https://doi.org/10.1016/j.chmed.2018.10.004 